\title{
Buildings Stability Revaluation in Seismically Active Regions
}

\author{
Natalia Koretskaya $^{1, *}$, and Nikolay Grib $^{2}$ \\ ${ }^{1}$ Technical Institute (branch) of North-Eastern Federal university after М.К. Аммоsov, Neryungri, \\ Russia \\ ${ }^{2}$ Technical Institute (branch) of North-Eastern Federal university after M.К. Аммоsov, Neryungri, \\ Russia
}

\begin{abstract}
In 2015 the maps of seismic zoning on the territory of Russia were detailed according to new general standards (OSR-2015). Compared to the previous data, the number of seismically dangerous areas has the tendency to increase. Most buildings in those areas of the country were designed and constructed as less earthquake resistant. The physical and mechanical characteristics of the soil in the buildings foundation are being changed under the influence of different ecological, engineering, geological, and man-made factors. The latest research discovers the high level of soil influence on seismic resistance of buildings. Further detailed examination of earthquake resistance of buildings in the northern territories of Russia has been planned according to the changes and influences mentioned above in order to lower the earthquake risks.
\end{abstract}

\section{Introduction}

The research of recent decades discovers the increasing risks of seismic disasters that can be connected with the human activities, different anthropogenic influences on the Earth's crust, geological, engineering, seismological, and environmental factors, as discussed in [1-3].

Latest Maps of General seismic zoning of the Russian Federation territory (GSZ-2015) have shown the following tendencies: the number of regions with high seismic risks has increased significantly compared to the previous data, as discussed in [4, 5]. For example, the earthquake in Neftegorsk in 1995 was estimated by experts as 9-10 points intensity. In the 60 's, these territories were not considered to be seismically active and the possibility of earthquakes was not taken into account in building construction. The understated estimates of seismic activity were made in Japan, China, Greece and other countries in the same period, as discussed in [1].

Consequently, buildings that were constructed a long period ago under the previous technical standards cannot be considered earthquake-proof now without pre-testing.

Moreover, well-designed and well-built dwellings must be operated properly. Temperature fluctuating, high air humidity and water-bearing soil as well as water-

* Corresponding author: coretskaya.nfygu@yandex.ru 
evaporating salts and the changes in water-bearing areas can cause the corrosion of concrete and metal in constructions. In the areas of permafrost like the Far East, the building earthquake resistance is greatly influenced by the changes of mixed soft ground condition that can lead to the building displacement under the seismic shocks. As it has already been mentioned, as described in [6], the sustainability of buildings that were constructed 30-40 years ago does not respond any more to modern climate conditions.

The major purpose of this research is to evaluate the building sustainability in the northern climate zone that's why the territory of Neryungri is now being under examination.

\section{Results}

To define the degree of seismic risks to buildings of different projects in South Yakutia the previous research was made in 2013-2014. As a result, detailed seismic zoning in Neryungri according to OSR-97B proved this territory to be of 8 points earthquake intensity. According to modern standards, $10.5 \%$ of residential and public buildings in Neryungri ( 25 houses and 2 kindergartens) are proved to be seismically non-resistant as they were built on the basis of seismic zoning map in USSR in 1969 when the earthquake intensity in this region was defined as 6-7 points intensity, (Fig.1), as described in [7]. Another study on seismic micro-zoning, as described in [7, 8], showed the high influence of ground conditions (the presence of decompressed unloading zone of a rock massif) on increasing the seismic impact on buildings.

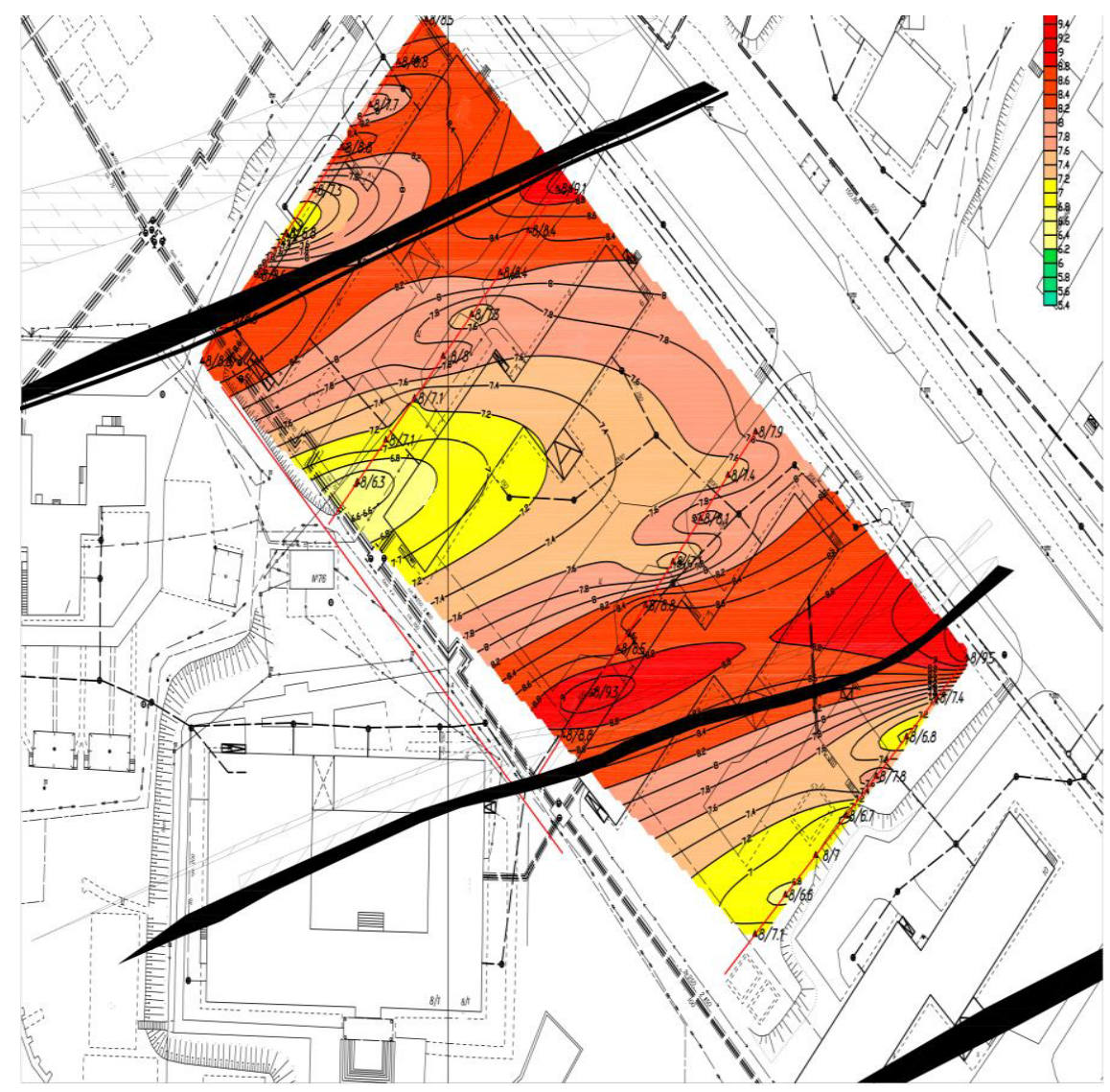

Fig.1. The Map of Microcalorimetry of Neryungri area 
Not only Neryungri, Serebryany Bor, Berkakit, Iengra but also the railway station in Chulman and Nagorny were in the grade 8 shock zone. The settlements of Hatymi and Nimnyr are situated in the grade 7-8 shock zone. (Fig. 2), as stated in [8]. 


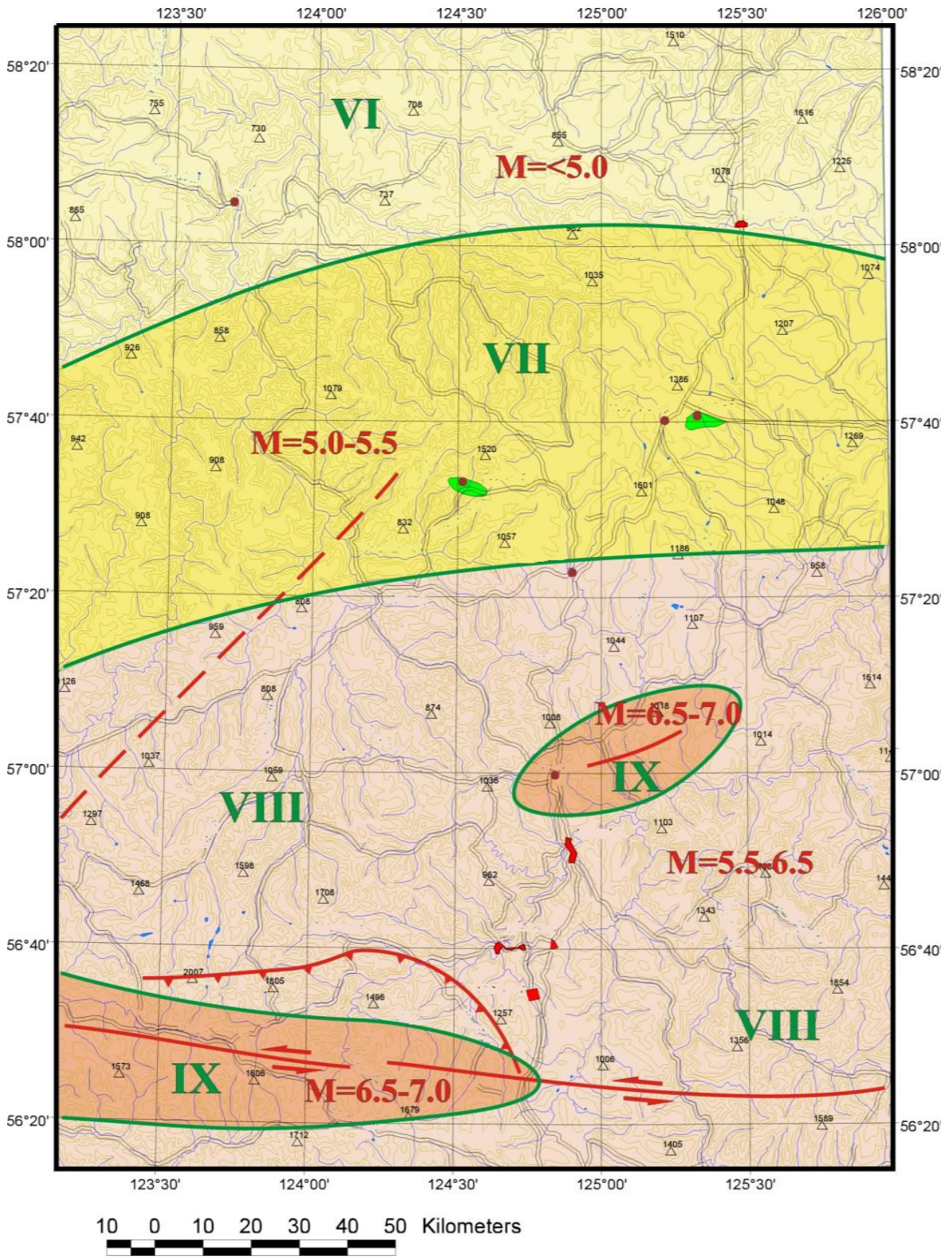

Fig.2. The Updated map of seismic zoning in Chulman fault.

Note: Red color shows the seismogenic faults. Green line marks the contours of the zones which magnitudes relevant in the range $\mathrm{M}=5.0-5.5-6.5-7.0$. Roman numerals indicate the intensity of the points on the scale MSK-6

\section{Discussion section}

The disagreement of seismicity amount with the actual conditions is due to several causes: 
- the methods applied for determining the earthquake-proof of buildings;

- the lack of proper control over the quality of seismic resistant construction;

- changing the geophysical characteristics of the base as a result of geological and climatic processes.

The number of geological and geophysical studies have been planned to specify in details the seismic influence and risks for the construction and operation of buildings under modern standards of safety, as described in [9]. Detailed micro-zoning of the territory will give the possibility to properly evaluate local climate conditions, seismic fluctuations, soft ground characteristics, topography, water-bearing nature, and other factors, described in [10].

\section{Conclusions}

The examination of seismic areas, as discussed in $[8,9]$ showed a high degree of ground conditions influence (the presence of different seals of zone of rock mass unloading) on the increasing level of potential seismic impacts on the facilities studied. The territory of Neryungri, estimated at OSR-97 maps as the territory of the border of possible 8 points shocks is estimated due to the scale of previous studies. When moving to another level of research quality (the enlargement of scale), it is possible to use a new class of activity maps of tectonic dynamics (they are detailed maps of seismotectonics) and to obtain more correct data that allow to determine the borders of score rating. When creating the map of possible earthquake foci a much more balanced assessment of seismic hazard was gained and it showed that in Neryungri area it can reach 8 points earthquakes intensity.

\section{References}

1. URL: http://www.rg.ru/Anons/arc 2002/0222/4.shtm (date of the address 11.10.2016)

2. N.I. Bojko, A.H. Avgucevichs, A.V. Safonov et. al. Tehnologii grazhdanskoj bezopasnosti 4 (46), 36-39 (2015)

3. V.A. Ljutoev, PhD Thesis (2002)

4. Change 1 to the joint venture 14.13330.2014, (2015)

5. V.I. Ulomov, Having tried to persuade V. I. The analysis of seismic danger of the Crimea and the North Caucasus, 13, 12-27 (2015)

6. A.B. Sherstyukov. PhD Thesis (2008)

7. S. Pavlov, V.S. Imaev, N.N. Grib and others. Report on accomplishment of seismological and geophysical works on an object (Nerjungristrojizyskanija, Republic of Sakha (2013)

8. I.I. Kolodeznikov, V.S. Imaev, N.N. Grib and others, Information report on research work (Respublika Saha, 2016)

9. 9.The joint venture 14.13330.2014 Construction in seismic countries Construction Norms and Regulations.

10. L.P. Imaeva, V.S. Imaev, O.P. Smekalin and others, Card of seismotectonics of Eastern Siberia (Nerjungri: Izd-vo Tehnicheskogo instituta SVFU (2015) 